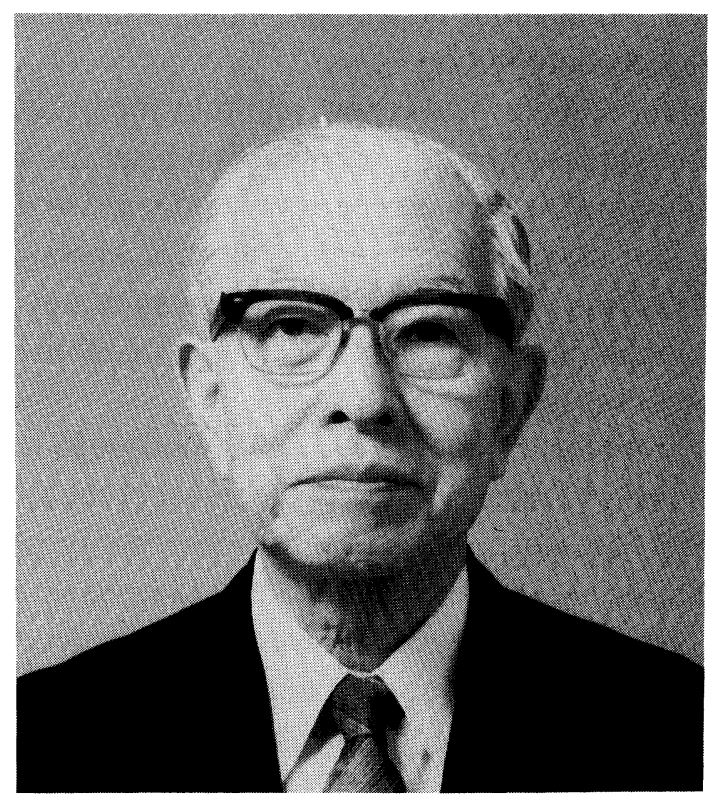

Masayoshi YAMAGUCHI, MD (1906.6.5-1997.12.31)

\title{
IN MEMORIAM: Masayoshi YAMAGUCHI, MD
}

It is with deep regret that we announce the passing away on December 31, 1997 of Dr. Masayoshi Yamaguchi. We have all lost a great leader, researcher and teacher in Dr. Yamaguchi, Director of the National Institute of Industrial Health since its inception in 1957 and Editor-in-Chief of both Industrial Health and its predecessor the Bulletin of Industrial Health, for the first 19 years from 1958 to 1976.

Dr. Yamaguchi graduated from the Faculty of Medicine of Tokyo Imperial University (which later became Tokyo University) in 1930 and then went to Yale University in the United States to study industrial health. After returning to Japan Dr. Yamaguchi worked in the Labor Bureau and the Public Health Bureau of the Ministry of Health and Welfare and made great efforts to improve labor and health standards in Japan. He participated in setting up the "Factory Physician System," the predecessor of the present "Industrial Health Administration System."

Together with the reconstruction of Japanese industry after 1945 there were calls for the establishment of a national research institute to conduct research on the prevention of a variety of occupational diseases, including pneumoconiosis, which was an important occupational health problem at the time. When the National Institute of Industrial Health was established in 1956, Dr. Yamaguchi, already well known for many scientific achievements, was asked by the Ministry of Labor to take on the task of being a 
director of the institute. At that time he was also Director of the Public Health Bureau of the Ministry of Health and Welfare.

At the time of establishment of the new institute for occupational health, Dr. Yamaguchi, in addition to research into occupational diseases, which until then had only been conducted by medical researchers, created a research institute with new functions, including non-medical fields such as physics, chemistry and mineralogy. He created the institute from the standpoint of preventing occupational diseases, thus helping to lay the foundation for the present National Institute of Industrial Health, which could respond to the needs of a new era.

Even after retiring from the institute in 1977, Dr. Yamaguchi continued his work in the areas of occupational and public health as a member of the Boards of Directors of the Occupational Welfare Corporation and the University of Occupational and Environmental Health, as the first Director of the Working Environment Measurement Association, Head of the Bioassay Research Center, Chairman of the Committee for the Industrial Health Consultant National Examination and as Chairman of the Board of Directors of the Japan Anti-Tuberculosis Association. In 1977 Dr. Yamaguchi was awarded the Order of the Rising Sun Gold and Silver Stars for his various achievements, such as his work as a member of numerous health-related government councils and committees, including the Silicosis Council.

The academic and administrative legacies left by Dr. Yamaguchi will in the future surely continue to inspire the National Institute of Industrial Health and its researchers.

Haruhiko SAKURAI

Editor-in-Chief, Industrial Health 